\title{
Repeat hepatectomy for recurred colorectal liver metastasis: is it justified?
}

\author{
Jangho Park', Seung-Duk Lee', Sung-Sik Han¹, Seoung Hoon Kim¹, Sang-Jae Park', Jae Hwan Oh², \\ Jungnam $\mathrm{Joo}^{3}$ \\ ${ }^{1}$ Center for Liver Cancer, National Cancer Center, Goyang, Korea \\ ${ }^{2}$ Center for Colorectal Cancer, National Cancer Center, Goyang, Korea \\ ${ }^{3}$ Biometrics Research Branch, Research Institute and Hospital, National Cancer Center, Goyang, Korea
}

\begin{abstract}
Purpose: Liver resection is considered the only curative treatment modality for colorectal liver metastasis. The recurrence rate after hepatectomy is $>50 \%$. Two or more hepatectomies are applied to treat recurred metastases. We assessed the efficiency and feasibility of repeat hepatectomy and analyzed the prognostic factors after a repeat hepatectomy.

Methods: In total, 248 patients were diagnosed with recurred liver metastasis between January 2003 and May 2016. Second and third hepatectomies were performed in 70 and 7 patients, respectively. The other 171 patients did not undergo a repeat hepatectomy. Clinical features were collected from the medical records. We analyzed survival rates of the repeat hepatectomy group and the nonrepeat hepatectomy group. We also investigated factors affecting overall and disease-free survival of patients who received a repeat hepatectomy using univariate and multivariate analyses.

Results: Median overall survival was significantly higher in the repeat hepatectomy group than in the nonrepeat group (83.0 months vs. 25.0 months, $\mathrm{P}<0.001$ ). The morbidity and mortality rates of repeat hepatectomy were $9.1 \%$ and $0 \%$, respectively. Median overall and disease-free survival of the repeat hepatectomy group were 62.0 and 51.0 months, respectively. The number of recurred tumors was the only significant factor for disease-free survival $(P=0.029)$. None of the factors affected overall survival.

Conclusion: Repeat hepatectomy is necessary, effective, and safe for treating recurred colorectal liver metastasis. Repeat hepatectomy can be considered in patients with fewer than three recurred metastatic tumors.
\end{abstract}

[Ann Surg Treat Res 2019;97(1):7-14]

Key Words: Colorectal neoplasms, Hepatectomy, Feasibility studies, Prognosis, Recurrence

\section{INTRODUCTION}

Colorectal liver metastasis (CRLM) occurs in approximately $50 \%$ of patients with primary colorectal cancer [1-3]. The liver is the most common organ to receive metastatic growth due to the portal venous system. Hepatic resection is considered the best treatment option for CRLM because it improves long-term survival [1,2].
A combination of surgery and systemic chemotherapy may offer longer survival rates [4,5]. The development of surgical skill and chemotherapeutic regimens has reinforced the effectiveness and efficiency of treatment. Moreover, chemotherapy also offers the possibility of hepatectomy even if metastatic tumors are not resectable at the initial presentation [6]. Systemic chemotherapy down-stages unresectable CRLM and leads to rescue surgeries.
Received December 18, 2018, Revised April 9, 2019,

Accepted April 26, 2019

Corresponding Author: Sung-Sik Han

Center for Liver Cancer, National Cancer Center, 323 IIsan-ro, Ilsandonggu, Goyang 10408, Korea

Tel: +82-31-920-1641, Fax: +82-31-920-1379

E-mail: sshan@ncc.re.kr

ORCID code: https://orcid.org/0000-0001-7047-7961
- This manuscript was an oral meeting presentation at the HBP Surgery Week \& the 48th Annual Congress of the HBP Surgery from March 30 to 31, 2018 in Busan, Republic of Korea.

Copyright (C) 2019, the Korean Surgical Society

(c) Annals of Surgical Treatment and Research is an Open Access Journal. All articles are distributed under the terms of the Creative Commons Attribution NonCommercial License (http://creativecommons.org/licenses/by-nc/4.0/) which permits unrestricted non-commercial use, distribution, and reproduction in any medium, provided the original work is properly cited. 
However, recurred CRLM after a liver resection has been reported in up to $80 \%$ of cases, regardless of these strategies, efforts, and surgical techniques [7-9]. Repeat hepatectomy has been used to treat recurrence. Several studies have reported that a second hepatectomy can be performed with acceptable morbidity and mortality, resulting in longer survival compared to the outcomes of a first hepatectomy [10-14]. The morbidity and mortality rates of repeat hepatectomy are $21.3 \%$ and $1.6 \%$, respectively [10].

In a previous study, the numbers, size, distribution, and appearance of metastatic tumors, serum levels of CEA, dimensions of the resection margin, and presence of extrahepatic metastasis were prognostic factors affecting the survival of patients who underwent a second hepatectomy [10].

In the current study, we evaluated the feasibility of repeat hepatectomy by investigating surgical outcomes at our institute and analyzed the prognostic factors of patients who underwent a repeat hepatectomy.

\section{METHODS}

\section{Patient selection}

In total, 593 patients underwent resection of primary colorectal cancer and liver metastases simultaneously or separately from March 2001 to December 2014 at the National Cancer Center, Korea, and 536 (90.4\%) received postoperative adjuvant chemotherapy. There were 248 recurrences after the initial operation: intrahepatic-only recurrence (202 patients) and both intrahepatic and extrahepatic recurrence (46 patients). Seventy-seven of these patients with recurred CRLM underwent a repeat hepatectomy between January 2003 and May 2016. These patients were in condition of resectable tumor with clear margin and residual volume of liver parenchyma more than $30 \%$. Furthermore, seven patients underwent a third hepatectomy after the second recurrence. The other 171 patients did not undergo a repeat hepatectomy (Fig. 1). Most patients in the nonrepeat hepatectomy group had multiple tumors in their remnant livers and their general condition was too poor to undergo an operation.

\section{Follow-up and surveillance after the initial operation}

Patients visited our outpatient department for regular followup after resection of primary and metastatic tumors. Diagnosis and surveillance of recurred CRLM were made based on serum levels of CEA and imaging studies of the liver such as dynamic computed tomography, magnetic resonance imaging with gadolinium ethoxybenzyl diethylenetriamine pentaacetic acid (Gd-EOB-DTPA), or fluorodeoxyglucose-positron emission tomography. We also evaluated the possibility of surgical resection with these modalities if there was any finding of recurrence.

\section{Clinical data collection}

The medical records were reviewed retrospectively to collect the clinical characteristics of the patients. The clinical data from the records were up to date until November 2016. The continuous variables included age, body mass index, American Society of Anesthesiologists physical status classification, preoperative and postoperative serum levels of CEA, tumor size, resection margin, and volume of total blood loss during the second hepatectomy. We defined 3 or more liver segmental resection as a major hepatectomy. We divided the location of primary colorectal cancer into 3 groups of right and left colon and the rectum. The $\mathrm{T}$ stage of the primary tumor was used to divide the patients into those with stages $\mathrm{T} 0$ and $\mathrm{T} 2$ and patients with stages T3 and T4. Four categories regarding patients' characteristics were formed: demographics, primary colorectal cancer, first hepatectomy, and second hepatectomy. This study was approved and the informed consent was waived by Institutional Review Board of our institution (NCC2017-0100).

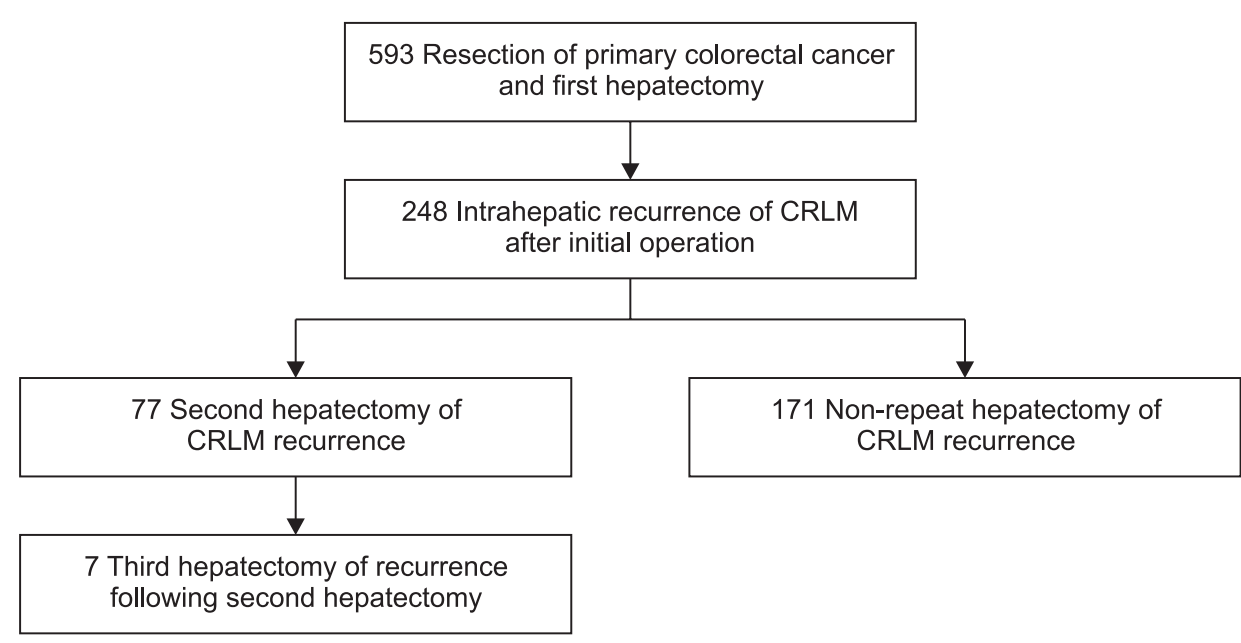

Fig. 1. Flow diagram for patient selection. CRLM, colorectal liver metastasis. 


\section{Statistical analyses}

Statistical analyses of the patient data were performed with SAS ver. 9.4 (SAS Institute, Cary, NC, USA) and R 3.3.3 (R Project for Statistical Computing, Vienna, Austria). We calculated overall survival (OS) and disease-free survival (DFS) using the Kaplan-Meier method. The prognostic factors affecting survival were analyzed using the Cox proportional hazards model. Factors with a P-value $<0.1$ in univariate analyses were assessed in multivariate analyses using a Cox test with backward variable elimination. P-values $<0.05$ were considered significant.

\section{RESULTS}

\section{Postoperative outcomes}

The intrahepatic recurrence rate of CRLM after the initial hepatectomy was $41.8 \%$ (248 of 593). Median time to recurrence following the first hepatectomy was 8.0 months. Seventyseven patients underwent a second hepatectomy for recurred CRLM. The nonrepeat hepatectomy group received alternative

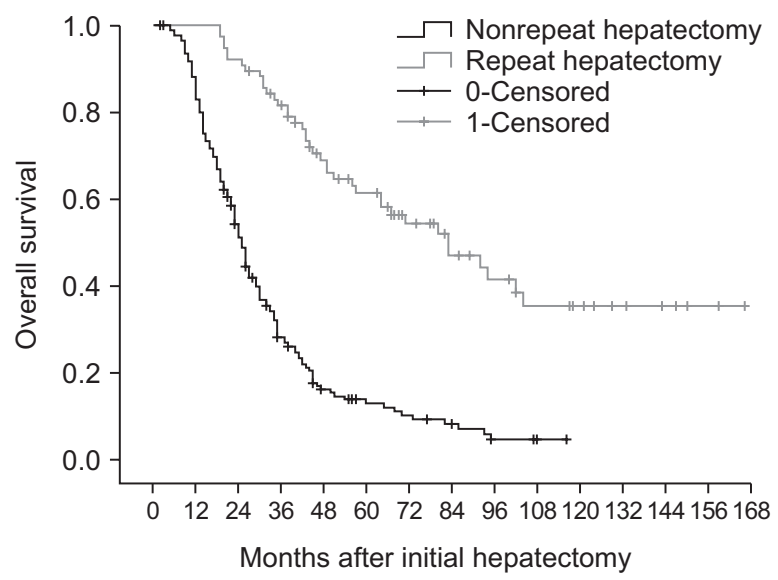

Fig. 2. Overall survival of the repeat hepatectomy and nonrepeat hepatectomy groups.

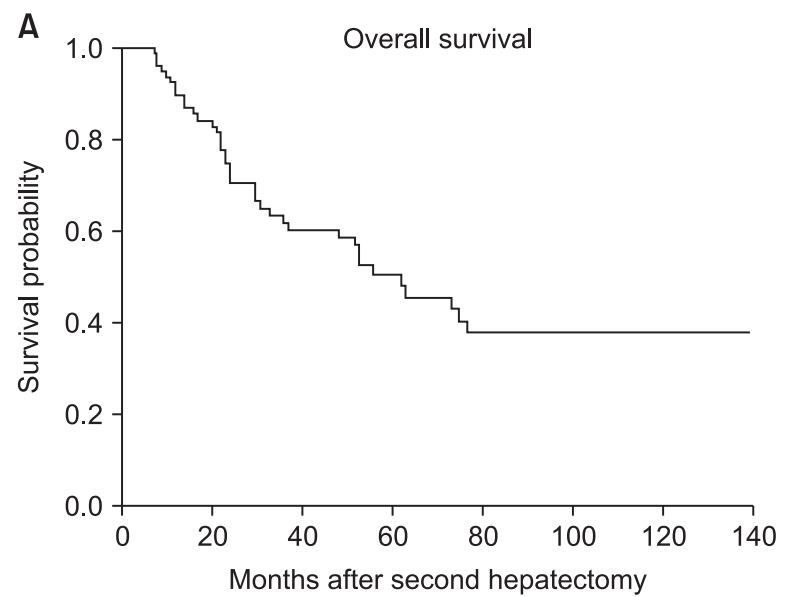

treatments: radiofrequency ablation $(\mathrm{RFA})(\mathrm{n}=9)$, palliative radiotherapy $(\mathrm{n}=3)$, systemic chemotherapy $(\mathrm{n}=117)$, and supportive care $(n=42)$. The median OS after the initial hepatectomy was higher in the repeat hepatectomy group (83.0 months) than in the nonrepeat hepatectomy group (25.0 months). Fig. 2 shows the difference in survival between the 2 groups. Seven patients who received a second hepatectomy underwent further resection because of relapsed hepatic metastasis. Table 1 shows the methods for the initial and second hepatectomies.

The morbidity and mortality rates of repeat hepatectomy

Table 1. Patient characteristics and methods of hepatectomy $(\mathrm{n}=77)$

\begin{tabular}{lc}
\hline \multicolumn{1}{c}{ Characteristic } & Value \\
\hline Age $(\mathrm{yr})$ & $56.6 \pm 10.6$ \\
Body mass index $\left(\mathrm{kg} / \mathrm{m}^{2}\right)$ & $24.0 \pm 3.0$ \\
First hepatectomy & 25 \\
Tumorectomy & 7 \\
Segmentectomy & 11 \\
Left lateral sectionectomy & 3 \\
Right posterior sectionectomy & 5 \\
Left trisectionectomy & 1 \\
Right trisectionectomy & 7 \\
Left hemihepatectomy & 18 \\
Right hemihepatectomy & \\
Second hepatectomy & 34 \\
Tumorectomy & 17 \\
Segmentectomy & 6 \\
Left lateral sectionectomy & 6 \\
Right posterior sectionectomy & 3 \\
Left trisectionectomy & 1 \\
Right trisectionectomy & 5 \\
Left hemihepatectomy & 5 \\
Right hemihepatectomy &
\end{tabular}

Values are presented as mean \pm standard deviation or number.

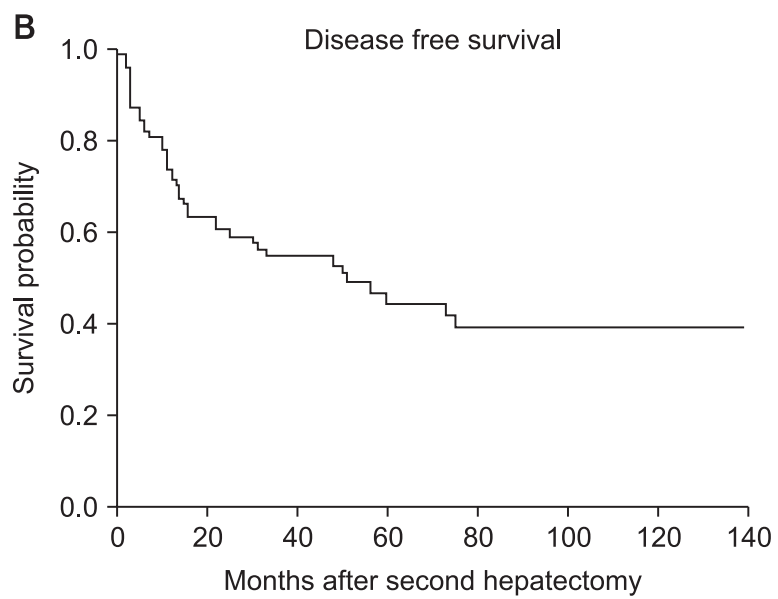

Fig. 3. Overall (A) and disease-free survival (B) rates of patients who underwent a second hepatectomy. 
Table 2. Analyses of prognostic factors after a second hepatectomy associated with disease-free intervals

\begin{tabular}{|c|c|c|c|c|c|c|c|}
\hline \multirow[b]{2}{*}{ Variable } & \multirow{2}{*}{$\begin{array}{c}\text { No. of } \\
\text { patients (\%) }\end{array}$} & \multicolumn{3}{|c|}{ Univariate analyses } & \multicolumn{3}{|c|}{ Multivariate analyses } \\
\hline & & $\begin{array}{c}\text { Hazard } \\
\text { ratio }\end{array}$ & $95 \% \mathrm{Cl}$ & P-value & $\begin{array}{l}\text { Hazard } \\
\text { ratio }\end{array}$ & $95 \% \mathrm{Cl}$ & P-value \\
\hline \multicolumn{8}{|l|}{ Demographics } \\
\hline \multicolumn{8}{|l|}{ Age $(y r)$} \\
\hline$<60$ & $45(58.4)$ & 1.00 & $0.44-1.53$ & 0.53 & & & \\
\hline$\geq 60$ & $32(41.6)$ & 0.82 & - & & & & \\
\hline \multicolumn{8}{|l|}{ Sex } \\
\hline Female & $18(23.4)$ & 1.00 & $0.44-1.82$ & & & & \\
\hline Male & $59(76.6)$ & 0.89 & - & 0.75 & & & \\
\hline \multicolumn{8}{|l|}{ Obesity $\left(\mathrm{BMl}, \mathrm{kg} / \mathrm{m}^{2}\right)$} \\
\hline$<25$ & $48(62.3)$ & 1.00 & $0.37-1.34$ & & & & \\
\hline$\geq 25$ & $29(37.7)$ & 0.7 & - & 0.29 & & & \\
\hline \multicolumn{8}{|l|}{ ASA PS classification } \\
\hline I & $32(41.6)$ & 1.00 & - & & & & \\
\hline II, III & $45(58.4)$ & 1.59 & $0.82-3.08$ & 0.17 & & & \\
\hline \multicolumn{8}{|l|}{ Primary colorectal cancer } \\
\hline \multicolumn{8}{|l|}{ Location } \\
\hline Right colon & $8(10.4)$ & 1.00 & $0.33-4.11$ & 0.44 & & & \\
\hline Left colon & $26(33.8)$ & 1.17 & $0.51-5.64$ & 0.81 & & & \\
\hline Rectum & $43(55.8)$ & 1.70 & - & 0.39 & & & \\
\hline \multicolumn{8}{|l|}{ No. of tumors } \\
\hline 1 & $74(96.1)$ & 1.00 & $0.20-3.37$ & & & & \\
\hline$\geq 2$ & $3(3.9)$ & 0.81 & - & 0.77 & & & \\
\hline \multicolumn{8}{|l|}{ Preoperative serum CEA (ng/dL) } \\
\hline$<5$ & $34(44.2)$ & 1.00 & $0.71-2.50$ & & & & \\
\hline$\geq 5$ & $43(55.8)$ & 1.33 & - & 0.37 & & & \\
\hline \multicolumn{8}{|l|}{ Preoperative hemotherapy } \\
\hline No & $53(68.8)$ & 1.00 & $0.56-2.11$ & & & & \\
\hline Yes & $24(31.2)$ & 1.09 & - & 0.80 & & & \\
\hline \multicolumn{8}{|l|}{ Postoperative pathology } \\
\hline Well differentiated adenocarcinoma & $7(9.1)$ & 1.00 & - & & & & \\
\hline $\begin{array}{l}\text { Moderate differentiated/mucinous } \\
\text { adenocarcinoma }\end{array}$ & $70(90.9)$ & 0.62 & $0.24-1.60$ & 0.33 & & & \\
\hline \multicolumn{8}{|l|}{ Tumor size $(\mathrm{cm})$} \\
\hline$<5$ & $39(50.7)$ & 1.00 & - & & & & \\
\hline$\geq 5$ & $38(49.3)$ & 1.32 & $0.72-2.45$ & 0.37 & & & \\
\hline \multicolumn{8}{|l|}{ T stage } \\
\hline T0, 1, 2 & $4(5.2)$ & 1.00 & $0.28-4.86$ & & & & \\
\hline $\mathrm{T} 3,4$ & $73(94.8)$ & 1.17 & - & 0.83 & & & \\
\hline \multicolumn{8}{|l|}{$\mathrm{N}$ stage } \\
\hline No & $8(10.4)$ & 1.00 & $0.22-1.95$ & 0.72 & & & \\
\hline N1 & $33(42.9)$ & 0.65 & $0.22-1.94$ & 0.44 & & & \\
\hline N2 & $36(46.7)$ & 0.65 & - & 0.44 & & & \\
\hline \multicolumn{8}{|l|}{ Postoperative serum CEA (ng/dL) } \\
\hline$<5$ & $60(77.9)$ & 1.00 & $0.74-2.96$ & & & & \\
\hline$\geq 5$ & $17(22.1)$ & 1.48 & - & 0.27 & & & \\
\hline \multicolumn{8}{|l|}{ Postoperative chemotherapy } \\
\hline No & $1(1.3)$ & 1.00 & $0.06-3.22$ & & & & \\
\hline Yes & $76(98.7)$ & 0.44 & - & 0.42 & & & \\
\hline
\end{tabular}


Table 2. Continued

\begin{tabular}{|c|c|c|c|c|c|c|c|}
\hline \multirow[b]{2}{*}{ Variable } & \multirow{2}{*}{$\begin{array}{c}\text { No. of } \\
\text { patients (\%) }\end{array}$} & \multicolumn{3}{|c|}{ Univariate analyses } & \multicolumn{3}{|c|}{ Multivariate analyses } \\
\hline & & $\begin{array}{l}\text { Hazard } \\
\text { ratio }\end{array}$ & $95 \% \mathrm{Cl}$ & P-value & $\begin{array}{l}\text { Hazard } \\
\text { ratio }\end{array}$ & $95 \% \mathrm{Cl}$ & P-value \\
\hline \multicolumn{8}{|l|}{ Tumor concurrency } \\
\hline Synchronous & $63(81.8)$ & 1.00 & $0.51-2.58$ & & & & \\
\hline Metachronous & $14(18.2)$ & 1.14 & - & 0.75 & & & \\
\hline \multicolumn{8}{|l|}{ First liver metastasis } \\
\hline \multicolumn{8}{|l|}{ Tumor distribution } \\
\hline Unilobe & $51(66.2)$ & 1.00 & $0.77-2.70$ & & & & \\
\hline Bilobes & $26(33.8)$ & 1.44 & - & 0.26 & & & \\
\hline \multicolumn{8}{|l|}{ Major hepatectomy } \\
\hline No & $41(53.3)$ & 1.00 & - & & & & \\
\hline Yes & $36(46.7)$ & 0.96 & $0.52-1.77$ & 0.88 & & & \\
\hline \multicolumn{8}{|l|}{ No. of tumors } \\
\hline$<3$ & $45(58.4)$ & 1.00 & $0.42-1.47$ & & & & \\
\hline$\geq 3$ & $32(41.6)$ & 0.78 & - & 0.44 & & & \\
\hline \multicolumn{8}{|l|}{ Tumor size $(\mathrm{cm})$} \\
\hline$<5$ & $69(89.6)$ & 1.00 & $0.31-2.46$ & & & & \\
\hline$\geq 5$ & $8(10.4)$ & 0.88 & - & 0.80 & & & \\
\hline \multicolumn{8}{|c|}{ Tumor resection margin $(\mathrm{cm})$} \\
\hline$<0.5$ & $32(41.6)$ & 1.00 & - & & & & \\
\hline$\geq 0.5$ & $45(58.4)$ & 0.86 & $0.47-1.59$ & 0.63 & & & \\
\hline \multicolumn{8}{|l|}{ Second liver metastasis } \\
\hline \multicolumn{8}{|l|}{ Tumor distribution } \\
\hline Unilobe & $69(89.6)$ & 1.00 & $0.18-1.89$ & & & & \\
\hline Bilobes & $8(10.4)$ & 0.58 & - & 0.37 & & & \\
\hline \multicolumn{8}{|l|}{ Major hepatectomy } \\
\hline No & $63(81.8)$ & 1.00 & - & & & & \\
\hline Yes & $14(18.2)$ & 0.81 & $0.36-1.84$ & 0.62 & & & \\
\hline \multicolumn{8}{|l|}{ No. of tumors } \\
\hline$<3$ & $68(88.3)$ & 1.00 & $0.99-5.06$ & & 1.00 & $1.10-5.73$ & \\
\hline$\geq 3$ & $9(11.7)$ & 2.24 & - & 0.05 & 2.51 & & 0.03 \\
\hline \multicolumn{8}{|l|}{ Tumor size $(\mathrm{cm})$} \\
\hline$<5$ & $69(89.6)$ & 1.00 & $0.53-3.49$ & & & & \\
\hline$\geq 5$ & $8(10.4)$ & 1.36 & - & 0.52 & & & \\
\hline \multicolumn{8}{|c|}{ Tumor resection margin $(\mathrm{cm})$} \\
\hline$<0.5$ & $37(48.1)$ & 1.00 & $0.37-1.27$ & & & & \\
\hline$\geq 0.5$ & $40(51.9)$ & 0.68 & - & 0.23 & & & \\
\hline \multicolumn{8}{|c|}{ Postoperative transfusion } \\
\hline No & $73(94.8)$ & 1.00 & $0.52-5.55$ & & & & \\
\hline Yes & $4(5.2)$ & 1.70 & - & 0.38 & & & \\
\hline \multicolumn{8}{|l|}{ Blood loss (mL) } \\
\hline$<500$ & $50(64.9)$ & 1.00 & $0.70-2.46$ & & & & \\
\hline$\geq 500$ & $27(35.1)$ & 1.31 & - & 0.40 & & & \\
\hline
\end{tabular}

$\mathrm{Cl}$, confidence interval; BMI, body mass index; ASA PS, American Society of Anesthesiologists physical status.

were $9.1 \%$ and $0 \%$, and the 3 - and 5-year survival rates were $61.7 \%$ and $50.1 \%$, respectively. Median OS was 62.0 months and median DFS was 51.0 months (Fig. 3). The morbidity and mortality rates of a third hepatectomy were $28.6 \%$ and $0 \%$, respectively. The 3-year OS rate was $57.1 \%$, and the 5-year survival rate was $28.6 \%$ after a third hepatectomy.

Seven patients developed complications after the second liver resection, including wound dehiscence $(\mathrm{n}=3)$, adhesive 


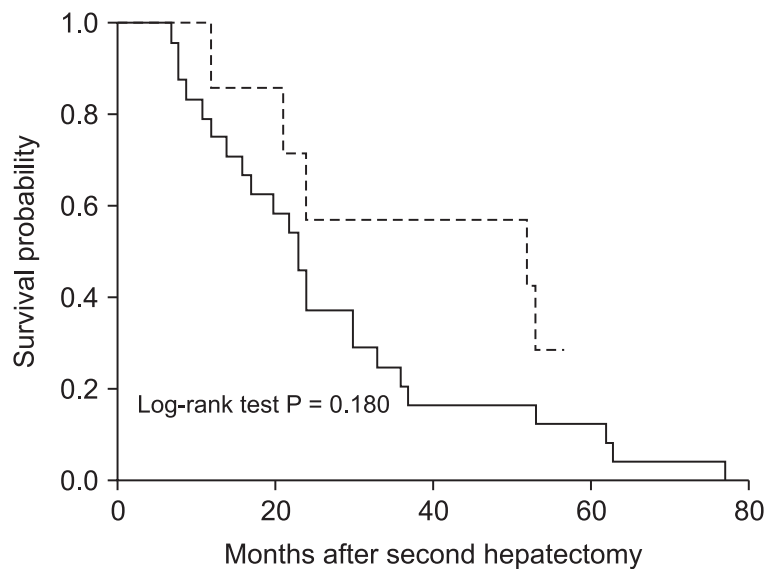

Fig. 4. Overall survival after a third hepatectomy (dotted line) and without a third hepatectomy (solid line).

ileus $(n=2)$, postoperative fluid collection $(n=1)$, and delirium $(\mathrm{n}=1)$. Only 2 patients had complications that were Clavien-Dindo classification grade $\geq$ III. Two patients had complications related to a third hepatectomy: pleural effusion and hepatic failure $(n=1)$ and pneumonia $(n=1)$. One patient received a postoperative blood transfusion following the third liver resection.

\section{Prognostic factors}

The number of recurred tumors was the only significant factor affecting DFS $(P=0.003)$ (Table 2$)$. No factor significantly affected OS. Thirty-one patients developed a rerecurrence following the repeat hepatectomy. Among these patients, the median OS rates of the third hepatectomy group $(n=7)$ and the non-third hepatectomy group $(n=24)$ were 52.0 and 23.0 months, respectively ( $\mathrm{P}=0.18$ ) (Fig. 4).

\section{DISCUSSION}

Treatment outcomes of CRLM have improved since the development of new chemotherapeutic regimens and surgical techniques. However, recurrence occurs in up to $80 \%$ of patients following resection of CRLM [7-9]. In our study, CRLM recurrence occurred in $41.8 \%$ of patients after the initial hepatectomy, although most patients underwent systemic chemotherapy following CRLM resection. A repeat hepatectomy can be performed very limitedly in patients with a CRLM recurrence. These limitations are due to extrahepatic metastases, low performance status of the patient, and diffuse distribution of intrahepatic tumors. Only 77 of 248 patients (31\%) with recurred CRLM underwent a repeat hepatectomy in this study. The median survival of the repeat hepatectomy group was higher than that of the nonrepeat hepatectomy group ( 83.0 months vs. 25.0 months). This result is at the upper range of that reported by Lopez et al. [10].

Factors influencing OS following repeat hepatectomy have been reported by several studies. Number, size, distribution, appearance, and resection margins of recurred metastases, serum levels of CEA, and presence of extrahepatic metastasis are significant prognostic factors of a repeat hepatectomy [10]. The greater the number of metastatic tumors, particularly more than two recurred CRLM tumors, suggests a lower rate of survival $[15,16]$. We found a significant difference in DFS between the patient group with 3 or more recurred tumors and patients with fewer than 3 tumors following the first hepatectomy. The numbers of initial metachronous or synchronous hepatic metastases from primary colon cancer prior to repeat hepatectomy were not related to OS or DFS in the present study. The size of a recurred tumor has been considered a crucial factor influencing survival. Patients with tumors $>5 \mathrm{~cm}$ have significantly shorter survival rates [1721]. Whether recurred CRLM tumors occur in a single liver lobe or both lobes determines the survival rate. Recurrence in both hemilivers shortens OS $[17,20]$. The period between the incidence of primary colon cancer and liver metastasis is considered a prognostic factor of repeat hepatectomy. Patients with metachronous CRLM, particularly with intervals $>6$ months or 1 year, have significantly poorer survival than patients with synchronous CRLM $[16,17,19,22]$. CEA levels prior to the first liver resection are a crucial factor, where higher levels imply a shorter survival rate $[15,18,21,23]$. R0 resection of the recurred tumor is also a factor impacting the survival rate. A reresection margin $>0.5 \mathrm{~cm}$ is a good prognostic factor [17,18]. However, none of these factors significantly affected OS or DFS in the current study.

Moreover, extrahepatic recurrence of CRLM is a poor prognostic factor $[15,21,24]$. Common locations for extrahepatic recurrence are the lung, bone, regional lymph nodes, and peritoneal dissemination. Sugawara et al. [24] suggested that metastases should be resected to improve survival when hepatic and pulmonary recurrences occur simultaneously. However, the present study focused on the liver, and no other metastatic organs were considered or investigated.

Morbidity and mortality are important therapeutic outcomes of repeat hepatectomy. Higher rates of morbidity and mortality of a repeat hepatectomy than those of the initial hepatectomy can be predicted due to adhesions, anatomical changes, and performance status of patients following a previous operation and chemotherapy. The morbidity and mortality rates in this study were $9.1 \%$ and $0 \%$, respectively.

Several studies have reported complications following repeat hepatectomy, such as bile leak, perihepatic abscess, hepatic failure, postoperative bleeding, peritonitis, refractory ascites, pleural effusion, and an adhesive small bowel obstruction $[2,25,26]$. Most of these complications were grade III or higher 
on the Clavien-Dindo classification grade. In the present study, the complications were wound dehiscence, adhesive ileus, delirium, pleural effusion, hepatic failure, and pneumonia. Only 2 patients had Clavien-Dindo classification grade $\geq$ III complications.

RFA has been suggested and attempted to treat CRLM [27]. However, this modality is exclusively selected for patients who are unable to tolerate a repeat hepatectomy. Wu et al. [28] demonstrated superior OS and local recurrence rates for surgical resection of tumors compared to RFA. RFA causes hypoxic injury to the tumor after an intervention and cluster of differentiation 95 has a role promoting the proliferation of tumors [29].

The limitations of this study include its retrospective nature and selection bias, as a repeat hepatectomy was applicable only to patients with resectable tumors. The study was also conducted at a single-center, so a multi-institute-based study should also be performed. We found no significant prognostic factors influencing survival rates compared to previous studies.
We did not exclude patients with poor general condition to receive second hepatectomy in nonrepeat hepatectomy group. Thus, standardization of patients in nonrepeat hepatectomy group should be considered to compare median OS with that of repeat hepatectomy group in similar conditions. Extrahepatic, pulmonary, and regional nodal metastases should also be investigated to determine their effects on prognosis.

In conclusion, the survival rate of the repeat hepatectomy group was longer than that of the nonrepeat hepatectomy group. Repeat hepatectomy is a safe and feasible modality to treat recurred CRLM. Although repeat hepatectomy may be more difficult than the first hepatectomy, it should be considered in patients with fewer than three tumors from recurred CRLM.

\section{CONFLICTS OF INTEREST}

No potential conflict of interest relevant to this article was reported.

\section{REFERENCES}

1. Altendorf-Hofmann A, Scheele J. A critical review of the major indicators of prognosis after resection of hepatic metastases from colorectal carcinoma. Surg Oncol Clin N Am 2003;12:165-92, xi.

2. Simmonds PC, Primrose JN, Colquitt JL, Garden OJ, Poston GJ, Rees M. Surgical resection of hepatic metastases from colorectal cancer: a systematic review of published studies. Br J Cancer 2006;94:982-99.

3. Yamada H, Kondo S, Okushiba S, Morikawa T, Katoh H. Analysis of predictive factors for recurrence after hepatectomy for colorectal liver metastases. World J Surg 2001;25:1129-33.

4. Brandi G, De Lorenzo S, Nannini M, Curti S, Ottone M, Dall'Olio FG, et al. Adjuvant chemotherapy for resected colorectal cancer metastases: literature review and meta-analysis. World J Gastroenterol 2016; 22:519-33.

5. Sargent D, Sobrero A, Grothey A, O'Connell MJ, Buyse M, Andre T, et al. Evidence for cure by adjuvant therapy in colon cancer: observations based on individual patient data from 20,898 patients on 18 randomized trials. J Clin Oncol 2009;27: 872-7.

6. Adam R, Delvart V, Pascal G, Valeanu A, Castaing D, Azoulay D, et al. Rescue surgery for unresectable colorectal liver metastases downstaged by chemotherapy: a model to predict long-term survival. Ann Surg 2004:240:644-57.

7. Saiura A, Yamamoto J, Koga R, Takahashi Y, Takahashi M, Inoue Y, et al. Favorable outcome after repeat resection for colorectal liver metastases. Ann Surg Oncol 2014; 21:4293-9.

8. Wicherts DA, de Haas RJ, Salloum C, Andreani P, Pascal G, Sotirov D, et al. Repeat hepatectomy for recurrent colorectal metastases. Br J Surg 2013;100:808-18.

9. Jones NB, McNally ME, Malhotra L, Abdel-Misih S, Martin EW, Bloomston M, et al. Repeat hepatectomy for metastatic colorectal cancer is safe but marginally effective. Ann Surg Oncol 2012;19:2224-9.

10. Lopez P, Marzano E, Piardi T, Pessaux P. Repeat hepatectomy for liver metastases from colorectal primary cancer: a review of the literature. J Visc Surg 2012;149:e97103.

11. Antoniou A, Lovegrove RE, Tilney HS, Heriot AG, John TG, Rees M, et al. Metaanalysis of clinical outcome after first and second liver resection for colorectal metastases. Surgery 2007;141:9-18.

12. Mise Y, Aloia TA, Brudvik KW, Schwarz L, Vauthey JN, Conrad C. Parenchymalsparing hepatectomy in colorectal liver metastasis improves salvageability and survival. Ann Surg 2016;263:146-52.

13. de Jong MC, Mayo SC, Pulitano C, Lanella S, Ribero D, Strub J, et al. Repeat curative intent liver surgery is safe and effective for recurrent colorectal liver metastasis: results from an international multiinstitutional analysis. J Gastrointest Surg 2009;13:2141-51.

14. Shaw IM, Rees M, Welsh FK, Bygrave S, John TG. Repeat hepatic resection for recurrent colorectal liver metastases is associated with favourable long-term survival. Br J Surg 2006;93:457-64.

15. Zacharias T, Jaeck D, Oussoultzoglou E, Bachellier P, Weber JC. First and repeat 
resection of colorectal liver metastases in elderly patients. Ann Surg 2004:240:858 65.

16. Ishiguro S, Akasu T, Fujimoto Y, Yamamoto J, Sakamoto Y, Sano T, et al. Second hepatectomy for recurrent colorectal liver metastasis: analysis of preoperative prognostic factors. Ann Surg Oncol 2006;13: 1579-87.

17. Tanaka K, Shimada H, Ohta M, Togo S, Saitou S, Yamaguchi S, et al. Procedures of choice for resection of primary and recurrent liver metastases from colorectal cancer. World J Surg 2004;28:482-7.

18. Nishio H, Hamady ZZ, Malik HZ, Fenwick S, Rajendra Prasad K, Toogood GJ, et al. Outcome following repeat liver resection for colorectal liver metastases. Eur J Surg Oncol 2007:33:729-34.

19. Ahmad A, Chen SL, Bilchik AJ. Role of repeated hepatectomy in the multimodal treatment of hepatic colorectal metastases. Arch Surg 2007;142:526-31.

20. Thelen A, Jonas S, Benckert C, Schu- macher G, Lopez-Hanninen E, Rudolph B, et al. Repeat liver resection for recurrent liver metastases from colorectal cancer. Eur J Surg Oncol 2007;33:324-8.

21. Pessaux P, Lermite E, Brehant O, Tuech JJ, Lorimier G, Arnaud JP. Repeat hepatectomy for recurrent colorectal liver metastases. J Surg Oncol 2006;93:1-7.

22. Sa Cunha A, Laurent C, Rault A, Couderc P, Rullier E, Saric J. A second liver resection due to recurrent colorectal liver metastases. Arch Surg 2007;142:1144-9.

23. Brachet D, Lermite E, Rouquette A, Lorimier G, Hamy A, Arnaud JP. Prognostic factors of survival in repeat liver resection for recurrent colorectal metastases: review of sixty-two cases treated at a single institution. Dis Colon Rectum 2009;52: 475-83.

24. Sugawara G, Isogai M, Kaneoka Y, Suzuki M, Yamaguchi A. Repeat hepatectomy for recurrent colorectal metastases. Surg Today 2005:35:282-9.

25. Battula N, Tsapralis D, Mayer D, Isaac J,
Muiesan P, Sutcliffe RP, et al. Repeat liver resection for recurrent colorectal metastases: a single-centre, 13-year experience. HPB (Oxford) 2014;16:157-63.

26. Fukami Y, Kaneoka Y, Maeda A, Takayama Y, Onoe S. Postoperative complications following aggressive repeat hepatectomy for colorectal liver metastasis have adverse oncological outcomes. Surg Today 2017;47:99-107.

27. Kim KH, Yoon YS, Yu CS, Kim TW, Kim HJ, Kim PN, et al. Comparative analysis of radiofrequency ablation and surgical resection for colorectal liver metastases. J Korean Surg Soc 2011;81:25-34.

28. Wu YZ, Li B, Wang T, Wang SJ, Zhou YM. Radiofrequency ablation vs hepatic resection for solitary colorectal liver metastasis: a meta-analysis. World J Gastroenterol 2011;17:4143-8.

29. Lee H, Choi SH, Cho YB, Yun SH, Kim HC, Lee WY, et al. Repeat hepatic resection in patients with colorectal liver metastases. World J Gastroenterol 2015;21:2124-30. 